\title{
Pengaruh E-Learning Readiness, Innovation, Performance Expectancy dan Perceived Usefulness terhadap Intention To Use E-Learning pada Perguruan Tinggi di Yogyakarta
}

\author{
(The Influence of E-Learning Readiness, Innovation, \\ Performance Expectancy and Perceived Usefulness \\ on the Intention to Use E-Learning \\ at Universities in Yogyakarta)
}

\author{
Dyah Sugandini ${ }^{*}$, Trestina Ekawati ${ }^{2}$, Rahajeng Arundati $^{3}$, Holimin $^{4}$ \\ 1,2 Fakultas Ekonomi dan Bisnis, Universitas Pembangunan Nasional "Veteran" Yogyakarta \\ ${ }^{3}$ Magister Sains Manajemen, Universitas Gadjah Mada Yogyakarta, ${ }^{4}$ Akademi Angkatan Udara \\ E-mail:dini@upnyk.ac.id,trestinae@gmail.com,ajeng.arundaty@gmail.com,holimin@aau.ac.id
}

\begin{abstract}
This study aims to re-analyze the intention to use e-learning which is influenced by elearning readiness, innovation, performance expectations, and perceived benefits. perceived usefulness mediates the relationship between e-learning readiness and innovation on intention to use e-learning. This study has a sample of 48 universities in Yogyakarta. Partial Least Square is used to test the hypothesis in this quantitative study. The test results found that the intention to use e-learning was positively and significantly influenced by e-learning readiness, innovation, performance expectations, and perceived benefits. Positively and significantly perceived usefulness mediates the relationship between e-learning readiness and innovation on intention to use e-learning.
\end{abstract}

Keywords—intention to use; e-learning; readiness; innovation; performance expectancy

Abstrak-Penelitian ini bertujuan untuk menganalisis kembali intention to use e-learning yang dipengaruhi oleh e-learning readiness, innovation, performance expectancy dan perceived usefullness. perceived usefullness memediasi hubungan antara e-learning readiness dan innovation terhadap intention to use e-learning. Penelitian ini memiliki jumlah sampel sebanyak 48 perguruan tinggi di Yogyakarta. Partial Least Square digunakan untuk menguji hipotesis pada penelitian kuantitatif ini. Hasil uji menemukan bahwa intention to use e-learning secara positif dan signifikan dipengaruhi oleh e-learning readiness, innovation, performance expectancy dan perceived usefulness. Perceived usefulness secara positif dan signifikan memediasi hubungan antara antara e-learning readiness dan innovation terhadap intention to use e-learning.

Kata Kunci- intention to use; e-learning; readiness; innovation; performance expectancy 


\section{Pendahuluan}

$\mathrm{T}$ knologi informasi dan komunikasi (TIK) dan teknologi digital secara aktif berkembang di bidang pendidikan. Saat ini, "Edu-tech" berjumlah sekitar 142 miliar dolar AS secara global, dan angka ini akan meningkat menjadi 342 miliar dolar AS pada tahun 2025 dalam Holon IQ tahun 2019. Adanya pandemi COVID-19 secara fundamental mempengaruhi lingkungan pendidikan. Perubahan ini tidak hanya berdampak pada siswa maupun mahasiswa tetapi juga guru dan dosen.[1] Hal ini mengakibatkan terhambatnya proses pembelajaran, karena dalam waktu singkat, semua kegiatan belajar mengajar, seperti perkuliahan, rapat, seminar, supervisi dan ujian terpaksa berpindah daring. [2] Sebuah studi internasional membandingkan situasi pandemi di Indonesia, Malaysia, Filipina, Irlandia, dan Finlandia.[3] Hasilnya menunjukkan bahwa situasi pandemi di negara-negara ini telah memperkenalkan serangkaian tantangan yang kompleks, mulai dari akses ke teknologi digital dan kesenjangan digital hingga pedagogi dan praktik akademik.

E-learning adalah Pembelajaran elektronik (e-learning) adalah pembelajaran yang memanfaatkan paket informasi berbasis teknologi informasi dan komunikasi untuk kepentingan pembelajaran yang dapat diakses oleh peserta didik kapan saja dan di mana saja.[4] E-learning juga merupakan proses pendidikan yang terorganisasi yang menjembatani keterpisahan antara siswa dengan pendidik dan dimediasi oleh pemanfaatan teknologi, dan pertemuan tatap muka yang minimal. E-learning adalah sikap positif dari peserta didik dan tenaga pendidik terhadap teknologi komputer dan internet, rancangan sistem pembelajaran yang dapat dipelajari/diketahui oleh setiap peserta belajar, sistem evaluasi terhadap kemajuan atau perkembangan belajar peserta belajar, dan mekanisme umpan balik yang dikembangkan oleh lembaga penyelenggara.[5]

Keberadaan e-learning memang dirasa perlu oleh mahasiswa maupun dosen. E-learning memberikan kemudahan bagi dosen untuk dapat menyajikan materi dengan berbagai variasi dengan teks, audio, atau vidio dan tau ketiganya. Dosen dapat mengemas materi materi yang disesuaikan dengan jenis materi yang akan disampaikan sehingga mahasiswa lebih mudah untuk memahaminya.[6] Dengan e-learning pula dosen secara tidak langsung dapat menggabungkan konsep strategi pembelajaran dengan cara memahami daya tangkap mahasiwa yang berbedabeda terhadap materi yang diberikan.

Namun demikian, untuk adopsi e-learning sendiri ternyata memerlukan tingkat kesiapan ( $e$ readiness) tinggi dari pihak perguruan tinggi, mahasiswa maupun para dosen. Priyanto mendefinisikan e-learning readiness sebagai kesiapan mental atau fisik suatu organisasi untuk suatu pengalaman pembelajaran.[7] Tidak hanya kesiapan yang dibutuhkan, Implementasi $e$ learning juga memerlukan kontribusi dari pihak institusi yaitu harapan kinerja (performance expectancy), dan tingkat kemanfaatan penerimaan (perceivec usefulness) dari objek e-learning itu sendiri [8]

Perguruan tinggi yang akan menerapkan inovasi e-learning dalam proses pembelajarannya harus memperhatikan $e$ - readiness, dan performance expectancy dari institusi. Kedua faktor tersebut sangat mempengaruhi minat penggunaan (intention to use $e$ learning) dan adopsi e-learning dimana objek dari penelitian ini adalah pemangku jabatan pada perguruan tinggi di Yogyakarta, penerapan e-learning di sejumlah perguruan tingggi Yogyakarta dirasa masih kurang dalam implementasi dan adopsi e-learning, dengan objek penelitian adalah pemangku jabatan pada perguruan tinggi yang mana tugas dan wewenangya adalah pegambil keputusan dalam sistem pembelajaran pada instansi perguruan tinggi, penelitian ini diharapkan dapat memberikan solusi atas intention to use elearning pada perguruan tinggi di Yogyakarta yang masih rendah. 
Topik ini menarik untuk diangkat karena negara kita merupakan negara berkembang. Dari segi Inovasi teknologi dan pemanfaatan sistem, mungkin "sedikit tertinggal" tak terkecuali sistem pendidikan yang berbasis online. Implementasinya bukan berarti salah namun tetap diperlukan perbaikan dalam hal integrasinya dengan management Institusi. Kajian ini mengulas kepentingan pembelajaran inovasi dibidang pembelajaran elektronik, kompetensi manajemen instanti dalam penerapan adopsi system, dan potret kesiapan dari objek-objek e-learning itu sendiri. Berdasarkan uraian yang telah disampaikan, maka penelitian ini mencoba menganalisis pengaruh e-learning readiness, innovation, dan performance expectancy terhadap intention to use e-learning dengan perceived usefulness sebagai mediasi (studi pada peguruan tinggi di yogyakarta).

\section{TINJAUAN PUSTAKA}

\section{A. E-learning Readiness.}

E-learning readiness menurut Walia merupakan tingkat dimana masyarakat disiapkan untuk berpartisipasi dalam teknologi dibidang pendidikan yang dapat membantu untuk membangun menuju masyarakat yang lebih baik. Menurut Borotis dan Poulymenakou, e-leraning readiness merupakan kesiapan mental atau fisik suatu organisasi untuk suatu pengalaman atau tindakan $e$ learning. Tingkat kesiapan mempunyai pengaruh yang besar dan linieritas yang tinggi terhadap intention to use e-learning, dengan kesiapan yang tinggi minat dan kecenderungan untuk mengadopsi e-learning juga semakin meningkat. Beberapa peneliti seperti Walia, Phan dan Dang, Glenda menemukan bahwa technology readiness terbukti memiliki dampak signifikan pada persepsi kemanfaatan sistem (perceived of usefulness).[9] Hasil ini menyiratkan bahwa semakin tinggi tingkat kesiapan institut dalam adopsi sistem e-learning maka minat dan keinginan untuk menggunakan e-learning juga semakin meningkat. Oleh karena itu, penelitian ini berhipotesis:

$\mathrm{H} 1$ : e-learning rediness berpengaruh langsng terhadap intention to use e-learning

$\mathrm{H} 2$ : e-learning readiness berpengaruh positif terhadap intention to use e-learning dengan perceived usefulness sebagai mediasi

\section{B. Innovation}

Inovasi tekonologi dalam bidang pendidikan adalah pembaruan dalam bidang pendidikan atau inovasi yang dilakukan untuk memecahkan masalah-masalah pendidikan, inovasi pendidikan merupakan suatu ide, barang, metode yang dirasakan atau diamati sebagai hal baru bagi seseorang atau kelompok orang (masyarakat) baik berupa hasil intervensi (yang baru) atau discovery (mengubah yang lama) yang digunakan untuk mencapai tujuan pendidikan atau memecahkan masalah-masalah pendidikan.[10] Inovasi dapat dilakukan dimana saja dan kapan saja. Khususnya dalambidang pendidikan, inovasi biasanya muncul dari adanya keresahan dan keinginan dari pihak-pihak tertentu tentang penyelenggaraan pendidikan. Turan menyimpulkan bahwa innovation memiliki pengaruh signifikan terhadap intention to use e- learning.[11]

Davis mendefinisikan persepsi kemanfaatan (perceived usefulness) sebagai sejauh mana seseorang percaya bahwa menggunakan suatu teknologi inovasi akan meningkatkan kinerja. Penelitian menunjukkan bahwa konstruk kemanfaatan persepsian (perceived usefulness) mempengaruhi secara positif dan signifikan.[12] Adanya inovasi teknologi memberikan gambaran baru pada aktivitas dibidang pendidikan, Adopsi e-learning menjadi suatu dominan aplikatif baru yang mulai dipelajari oleh berbagai instansi pendidikan. Oleh karena itu, penelitian ini berhipotesis: 
$\mathrm{H} 3$ : innovation perngaruh langsung terhadap intention to use e-learning

$\mathrm{H} 4$ : innovation berpengaruh positif terhadap intention to use e-learning dengan perceived usefulness sebagai mediasi.

\section{Performance Expectancy}

Beberapa penelitian sebelumnya telah menunjukkan bahwa performance expectancy adalah salah satu faktor yang paling tepat untuk memprediksi niat individu untuk menggunakan teknologi, terutama dalam pengaturan pendidikan.[13] Menurut Venkatesh performance expectancy didefinisikan sebagai "sejauh mana seorang individu percaya bahwa sistem membantu untuk meningkatkan kinerja pekerjaan". Selain itu, seorang individu mungkin lebih cenderung menggunakan teknologi baru jika dia menemukan bahwa itu meningkatkan kinerja.[14] Dalam konteks penelitian ini (pendidikan tinggi), siswa maupun mahasiswa akan lebih cenderung menggunakan teknologi untuk tujuan pembelajaran. Dengan kata lain, performance expectancy mewakili keyakinan mereka tentang apakah penggunaan teknologi digital akan meningkatkan kinerja belajar mereka. Dengan demikian, hipotesis penelitian ini adalah sebagai berikut:

H5: performance expectancy berpengaruh postitif terhadap intention to use e-learning

\section{Perceived Usefulness}

Beberapa peneliti terdahulu telah meneliti minat untuk menggunakan inovasi pembelajaran online atau e-learning, Chen, Tseng, Veloo dan Masood, menyimpulkan bahwa perceived usefulness memiliki pengaruh positif signifikan terhadap intention to use e-learning.[15] Hasil penelitian ini juga sejalan dengan penelitian Lee, Hsieh, Chen dan Nursiah dimana dengan tegas menyatakan perceived usefulness memiliki pengaruh terhadap niat untuk menggunakan.[16] Selanjutnya dari hasil penelitian Lwoga, diketahui bahwa niat atau keinginan berperilaku untuk adopsi teknologi baru lebih kuat ditentukan oleh perceived usefulness dibandingkan dengan norma subjektif.[17] Hasil analisis yang dilakukan dalam penelitian ini menunjukkan bahwa perceived usefulness berpengaruh terhadap intention to use. Dengan demikian, hipotesis penelitian ini adalah sebagai berikut:

H6: perceived usefulness berpengaruh postitif terhadap intention to use e-learning

\section{Metodologi}

Penelitian ini menggunakan jenis penelitian kuantitatif. Metode penelitian kuantitatif merupakan metode penelitian berlandaskan pada filsafat positivism, metode ini digunakan untuk meneliti populasi dan sampel.[18] Populasi pada penelitian ini adalah seluruh perguruan tinggi di Yogyakarta yang populasinya berjumlah 104 perguruan tinggi. Dalam penelitian ini, sampel yang diambil adalah 48 perguruan tinggi di Kota Yogyakarta. Responden dalam penelitian ini diwakilkan oleh para pemangku jabatan pada Perguruan tinggi di Yogyakarta. Kuesioner ini disebarkan secara cluster random sampling yakni sejumlah 48 Perguruan tinggi dengan 80 kuesioner. Berikut karakteristik responden pada penelitian ini:ormat tabel dibuat seperti contoh. Garis tabel bagian paling atas dan paling bawah selalu dibuat ganda. Nama tabel ditulis di atas tabel dengan style Table Title, seperti contoh Tabel 1. 
TABEL I

KARAKTERISTIK RESPONDEN

\begin{tabular}{|c|l|c|r|}
\hline \hline \multicolumn{2}{|c|}{ Karakteristik } & Frekuensi & Presentase \\
\hline \multirow{3}{*}{ Jabatan Responden } & Pimpinan perguruan tinggi & 33 & $68,75 \%$ \\
\cline { 2 - 4 } & Pengelola/Manajemen & 15 & $31,25 \%$ \\
\hline \multirow{3}{*}{$\begin{array}{l}\text { Lama penggunaan sistem } \\
\text { - learning }\end{array}$} & $<5$ tahun & 22 & $45,83 \%$ \\
\cline { 2 - 4 } & $5-10$ tahun & 22 & $45,83 \%$ \\
\cline { 2 - 4 } Jenis e-learning & $>10$ tahun & 4 & $8,33 \%$ \\
\hline \multirow{3}{*}{ Jumlah teknisi sistem } & Berbasis Web & 35 & $72,92 \%$ \\
\cline { 2 - 4 } & Google classroom & 5 & $10,42 \%$ \\
\cline { 2 - 4 } & Lainnya & 35 & $16,67 \%$ \\
\cline { 2 - 4 } & $>10$ karyawan & 11 & $72,92 \%$ \\
\cline { 2 - 4 } & $10-20$ karyawan & 2 & $22,92 \%$ \\
\hline \hline
\end{tabular}

\section{HASIL PENELITIAN}

Pada penelitian ini, pengujian hipotesis menggunakan teknik analisis Partial Least Square (PLS) dengan program Smart PLS 3.0. Teknik ini terdiri dari 3 komponen, yaitu outer model atau measurement model, inner model atau structural model dan skema model. [19] Outer model atau measurement model adalah model pengukuran yang menghubungkan indikator dengan variabel lainnya dan inner model atau structural model adalah model struktural yang menghubungkan antar variabel laten. Outer model atau uji indikator indikator reflektif dievaluasi melalui convergent validity, discriminant validity, dan AVE. Sementara uji reliabilitas dilihat dari nilai composite reliability dan cronbach alpha. Data yang valid dan reliabel bernilai > 0.7 dan nilai AVE yang diharapkan > 0.5, masing-masing konstruk yang ditunjukkan pada Tabel 2 memiliki kriteria di atas strandar yang telah diharapkan. Sementara itu, discriminant validity dievalusi dengan membandingkan nilai loading pada konstruk yang dituju harus lebih besar dibandingkan dengan nilai loading dengan konstruk yang lain. Tabel III menyajikan hasil pengujian discriminant validity, yakni menunjukkan bahwa masing-masing nilai loading pada konstruk yang dituju lebih besar dibandingkan dengan nilai loading konstruk yang lain.

TABEL II.

CONSTRUCT RELIABILITY AND VALIDITY

\begin{tabular}{|l|c|c|c|}
\hline \multicolumn{1}{|c|}{ Variabel } & AVE & $\begin{array}{c}\text { Composite } \\
\text { Reliability }\end{array}$ & $\begin{array}{c}\text { Cronbachs } \\
\text { Alpha }\end{array}$ \\
\hline E-Readiness & 0.640 & 0.961 & 0.957 \\
\hline Innovation & 0.637 & 0.925 & 0.905 \\
\hline Performance Expectancy & 0.623 & 0.943 & 0.933 \\
\hline Intention to Use E-Learning & 0.582 & 0.917 & 0.897 \\
\hline Percieved Usefullness & 0.624 & 0.930 & 0.914 \\
\hline \hline
\end{tabular}


TABEL III

CROSS LOADING

\begin{tabular}{|c|c|c|c|c|c|}
\hline Indikator & $\begin{array}{l}\text { Elearning } \\
\text { Readiness }\end{array}$ & Innovation & $\begin{array}{l}\text { Performance } \\
\text { Expectancy }\end{array}$ & $\begin{array}{c}\text { Intention to Use } \\
\text { E-Learning }\end{array}$ & $\begin{array}{c}\text { Percieved } \\
\text { Usefullness }\end{array}$ \\
\hline X1.1 & 0.765 & 0.571 & 0.459 & 0.568 & 0.500 \\
\hline $\mathrm{X} 1.10$ & 0.784 & 0.597 & 0.371 & 0.681 & 0.602 \\
\hline $\mathrm{X} 1.11$ & 0.801 & 0.508 & 0.390 & 0.645 & 0.567 \\
\hline $\mathrm{X} 1.12$ & 0.763 & 0.469 & 0.330 & 0.616 & 0.543 \\
\hline $\mathrm{X} 1.13$ & 0.804 & 0.602 & 0.423 & 0.711 & 0.611 \\
\hline $\mathrm{X} 1.14$ & 0.782 & 0.539 & 0.485 & 0.697 & 0.615 \\
\hline X1.2 & 0.851 & 0.538 & 0.337 & 0.605 & 0.466 \\
\hline $\mathrm{X} 1.3$ & 0.848 & 0.565 & 0.361 & 0.659 & 0.562 \\
\hline $\mathrm{X} 1.4$ & 0.801 & 0.562 & 0.331 & 0.614 & 0.422 \\
\hline $\mathrm{X} 1.5$ & 0.782 & 0.569 & 0.370 & 0.629 & 0.522 \\
\hline $\mathrm{X} 1.6$ & 0.824 & 0.642 & 0.436 & 0.680 & 0.610 \\
\hline $\mathrm{X} 1.7$ & 0.795 & 0.540 & 0.271 & 0.541 & 0.393 \\
\hline $\mathrm{X} 1.8$ & 0.780 & 0.523 & 0.307 & 0.609 & 0.504 \\
\hline X1.9 & 0.819 & 0.586 & 0.324 & 0.645 & 0.526 \\
\hline $\mathrm{X} 2.1$ & 0.453 & 0.533 & 0.846 & 0.597 & 0.588 \\
\hline $\mathrm{X} 2.2$ & 0.336 & 0.444 & 0.764 & 0.501 & 0.487 \\
\hline $\mathrm{X} 2.3$ & 0.365 & 0.479 & 0.796 & 0.534 & 0.515 \\
\hline X2.4 & 0.347 & 0.490 & 0.790 & 0.558 & 0.527 \\
\hline X3.1 & 0.605 & 0.821 & 0.569 & 0.710 & 0.671 \\
\hline $\mathrm{X} 3.2$ & 0.400 & 0.764 & 0.415 & 0.576 & 0.480 \\
\hline $\mathrm{X} 3.3$ & 0.585 & 0.812 & 0.450 & 0.608 & 0.567 \\
\hline X3.4 & 0.621 & 0.829 & 0.418 & 0.662 & 0.525 \\
\hline $\mathrm{X} 3.5$ & 0.532 & 0.819 & 0.449 & 0.638 & 0.551 \\
\hline X3.6 & 0.574 & 0.813 & 0.579 & 0.759 & 0.640 \\
\hline $\mathrm{X} 3.7$ & 0.568 & 0.726 & 0.518 & 0.633 & 0.520 \\
\hline Y1.1 & 0.493 & 0.596 & 0.614 & 0.716 & 0.600 \\
\hline Y1.2 & 0.656 & 0.542 & 0.581 & 0.747 & 0.715 \\
\hline Y1.3 & 0.555 & 0.701 & 0.539 & 0.761 & 0.623 \\
\hline Y1.4 & 0.741 & 0.744 & 0.571 & 0.828 & 0.709 \\
\hline Y1.5 & 0.580 & 0.572 & 0.538 & 0.770 & 0.695 \\
\hline Y1.6 & 0.576 & 0.626 & 0.528 & 0.763 & 0.621 \\
\hline Y1.7 & 0.583 & 0.654 & 0.502 & 0.775 & 0.658 \\
\hline Y1.8 & 0.671 & 0.598 & 0.526 & 0.738 & 0.650 \\
\hline Z1.1 & 0.483 & 0.522 & 0.514 & 0.618 & 0.783 \\
\hline Z1.2 & 0.557 & 0.559 & 0.573 & 0.697 & 0.774 \\
\hline Z1.3 & 0.539 & 0.560 & 0.501 & 0.692 & 0.817 \\
\hline $\mathrm{Z1.4}$ & 0.480 & 0.412 & 0.460 & 0.571 & 0.771 \\
\hline $\mathrm{Z} 1.5$ & 0.606 & 0.687 & 0.565 & 0.730 & 0.768 \\
\hline Z1.6 & 0.508 & 0.549 & 0.509 & 0.684 & 0.726 \\
\hline Z1.7 & 0.539 & 0.603 & 0.521 & 0.754 & 0.845 \\
\hline Z1.8 & 0.515 & 0.575 & 0.531 & 0.690 & 0.831 \\
\hline
\end{tabular}


TABEL IV

HASIL UJI BOOTSTRAPPING

\begin{tabular}{|l|c|c|c|c|c|c|}
\hline \hline Hypothesis & $\begin{array}{c}\text { Original } \\
\text { Sample (O) }\end{array}$ & $\begin{array}{c}\text { Sample } \\
\text { Mean (M) }\end{array}$ & $\begin{array}{c}\text { Standard } \\
\text { Deviation } \\
\text { (STDEV) }\end{array}$ & $\begin{array}{c}\text { T-Statistics } \\
(\mid \mathrm{O} / \mathrm{STDEV})\end{array}$ & $\begin{array}{c}\boldsymbol{P} \text { - } \\
\text { Values }\end{array}$ & Keterangan \\
\hline $\begin{array}{l}\text { E-Readiness } \rightarrow \\
\text { Intention to Use E- } \\
\text { Learning }\end{array}$ & 0.295 & 0.309 & 0.102 & 2.626 & $\mathbf{0 . 0 0 9}$ & Diterima \\
\hline $\begin{array}{l}\text { E-Readiness } \rightarrow \\
\text { Percieved Usefullness } \\
\begin{array}{l}\text { Intention to Use E- } \\
\text { Learning }\end{array}\end{array}$ & 0.116 & 0.109 & 0.045 & 2.588 & $\mathbf{0 . 0 1 0}$ & Diterima \\
\hline $\begin{array}{l}\text { Innovation } \rightarrow \text { Intention } \\
\text { to Use E-Learning }\end{array}$ & 0.239 & 0.232 & 0.087 & 2.305 & $\mathbf{0 . 0 2 2}$ & Diterima \\
\hline $\begin{array}{l}\text { Innovation } \rightarrow \\
\text { Percieved Usefullness } \\
\begin{array}{l}\text { Intention to Use E- } \\
\text { Learning }\end{array}\end{array}$ & 0.106 & 0.102 & 0.043 & 2.445 & $\mathbf{0 . 0 1 5}$ & Diterima \\
\hline $\begin{array}{l}\text { Performance } \\
\text { Expectancy } \rightarrow \\
\text { Intention to Use E- } \\
\text { Learning }\end{array}$ & 0.190 & 0.197 & 0.061 & 2.394 & $\mathbf{0 . 0 1 7}$ & Diterima \\
\hline $\begin{array}{l}\text { Percieved } \\
\text { Usefullness } \\
\text { Intention to Use E- } \\
\text { Learning }\end{array}$ & 0.371 & 0.360 & 0.065 & 5.432 & $\mathbf{0 . 0 0 0}$ & Diterima \\
\hline \hline
\end{tabular}

\section{Pembahasan}

Menurut Borotis dan Poulymenakou, e-leraning readiness merupakan kesiapan mental atau fisik suatu organisasi untuk suatu pengalaman atau tindakan e-learning. Tingkat kesiapan mempunyai pengaruh yang besar dan linieritas yang tinggi terhadap intention to use e-learning, dengan kesiapan yang tinggi minat dan kecenderungan untuk mengadopsi e-learning juga semakin meningkat. Penelitian ini sejalan dengan penelitian yang dilakukan oleh Glenda tahun 2016 yang menyimpulkan bahwa e-learning Readiness berpengaruh positif dan signifikan terhadap Intention to use e- Learning. Penelitian lain yang dilakukan oleh Walia tahun 2019 dan Roni Falash juga menyimpulkan bahwa tingkat kesiapan suatu e-readiness berpengaruh positif terhadap intenttion to use e-learning, semakin tinggi tingkat kesiapan institut dalam adopsi sistem e-learning maka minat dan keinginan untuk menggunakan e-learning juga semakin meningkat.[20] Penelitian ini secara konsisten menunjukkan hubungan readiness yang berpengaruh signfikan terhadap minat untuk menggunakan e-learning, semakin tinggi tingkat keisapan e-learning semakin mudah pula adopsi sistem tersebut. Artinya bahwa berdasarkan responden, perguruan tinggi di Daerah Istimewa Yogyakarta dianggap secara positif dapat mempengaruhi untuk meningkatkan minat menggunakan sistem pembelajaran e-learning pada perguruan tinggi.

Hasil penelitian ini menunjukkan bahwa inovasi berpengaruh terhadap intention to use elearning. Semakin tinggi tingkat Inovasi yang digunakan, maka intention to use e-learning-nya 
pun akan meningkat. Inovasi memiliki hubungan yang kuat dengan Intention to use e-learning yang dilakukan oleh perguruan tinggi khususnya dalam sistem pembelajaran yang diberikan. Maka dari itu perguruan tinggi di Yogyakarta harus selalu melakukan Inovasi baru untuk menunjang dan meningkatkan intention to use e-learning perguruan tinggi itu sendiri. Inovasi dilakukan untuk mempertahankan keterbaharuan, kemanfaatan dan kualitas dari sistem pembelajaran di perguruan tinggi. Hasil penelitian ini sesuai dengan temuan Aykut Hamit Turan dan Naciye Güliz Uğurn yang mengatakan bahwa Inovasi berpengaruh signifikan terhadap intention to use e-learning dibidang pendidikan.

Berdasarkan uji hipotesis menyatakan bahwa innovation berpengaruh tidak langsung terhadap intention to use e-learning yang dimediasi oleh perceivec usefulness diterima. Terbukti dengan original sampel sebesar 0,239 dengan nilai t hitung 2,305 dengan nilai p 0,022 yang lebih kecil nilai kritisnya $\mathrm{P}<0,05$, maka Perceived usefulness mampu memediasi pengaruh Innovation terhadap intention to use e-learning. Artinya dengan adanya perceived usefulness maka pengaruh innovation terhadap intention to use e-learning semakin tinggi. Hasil penelitian ini sesuai dengan temuan Teoh dan Tan tahun 2020 yang mengatakan bahwa inovasi tidak berpengaruh secara langsung terhadap intention to use, namun harus dimediasi oleh variabel perceived usefulness terlebih dahulu.[21] Penelitian tersebut menyimpulkan bahwa pengaruh inovasi khususnya dibidang teknologi memberikan pengaruh kepada intention to use yang kemudian juga meningkatkan dampak untuk meningkat minat responden untuk menggunakan $e$ learning.

Hasil uji hipotesis pada penelitian ini menyatakan perceived usefulness berpengaruh langsung terhadap intention to use e-learning diterima. Terbukti dengan koefisien regresi/O sampel sebesar 0,371 dengan nilai t hitung 5,432 dengan nilai values 0.000 lebih kecil dari 0,050. Hasil ini diartikan bahwa Perceived usefulness berpengaruh positif dan signifikan terhadap intention to use e-learning pada perguruan tinggi di Yogyakarta artinya apabila Perceived usefulness menunjukan angka yang baik maka akan meningkatkan intention to use $e$ learning, begitu sebaliknya. Dalam hal ini lebih dikaitkan keada minat untuk menggunakan inovasi pembelajaran online atau e-learning, Hasil dari pengujian hipotesis sejalan dengan penelitian Tao (2019), dimana perceived usefulness memiliki dampak yang signifikan pada kedua niat untuk menggunakan dan penggunaan aktual dari eresources sementara efek kemudahan penggunaan pada niat untuk menggunakan dan penggunaan aktual dimediasi oleh perceived usefulness. Hasil penelitian ini juga sejalan dengan penelitian Nursiah, dimana dengan tegas menyatakan perceived usefulness memiliki pengaruh terhadap niat untuk menggunakan e-learning.

\section{KESIMPULAN}

Penelitian yang telah dilakukan menunjukkan bahwa tingkat kesiapan e-learning (e-learning readiness), inovasi (innovation) dalam teknologi baru, dan harapan kinerja (performance expectancy) dari e-learning, dengan manfaat yang dirasakan (perceived usefulness) sebagai mediasi mempunyai pengaruh terhadap minat suatu perguruan tinggi terus menggunakan $e$ learning (Intention to use e-learning) yang digunakan pada perguruan tinggi.

\section{Keterbatasan dan Saran}

Berdasarkan hasil penelitian ini, penelitian ini memiliki beberapa keterbatasan, sehingga peneliti dapat memberikan saran yang diharapkan akan bermanfaat bagi penelitian selanjutnya. Pertama, sampel pada penelitian ini terbatas pada daerah tertentu yaitu Daerah Istimewa Yogyakarta. Oleh karena itu, generalisasi dari model kognitif masih perlu divalidasi lebih lanjut 
pada daerah lain. Perbedaan karakteristik dari masing-masing universitas yang tersebar di indonesia sangat beragam, penggunaan sistem e-learning yang bermacam-macam juga perlu digali lebih lanjut. Aspek-aspek yang lain yang menjadi kendala adopsi e-learning dan penggunaan e-learning menjadi peluang untuk peneliti selanjutnya untuk mengembangkan penelitian empiris lebih jauh.

Kedua, meskipun penelitian ini membentuk model kognitif dari tingkat kesiapan serta kemanfaatan yang dirasakan (perceived usefulness) telah digunakan, tetapi berdasarkan aspek teoritis, studi pada tingkat minat menggunakan $e$ - learning di perguruan tinggi masih memberikan peluang pengembangan untuk menambahkan faktor lain sebagai antesedent model adopsi dan minat menggunakan e-learning, seperti system quality, perceived use to easy, behavior student, information quality, quality of service dan sebagainya.

Ketiga, penelitian ini menunjukkan bahwa variabel kemudahan yang dirasakan (perceived usefulness) pengguna e-learning memiliki pengaruh yang paling besar terhadap intention to use e-learning. Oleh karena itu, perguruan tinggi dan pemerintah perlu lebih mempromosikan mengenai kemudahan yang dirasakan serta manfaat yang akan diperoleh ketika seluruh perguruan tinggi di Indonesia menggunakan sistem pembelajaran berbasis e-learning, kemudahan akan dirasakan oleh tenaga pendidik (dosen) atau mahasiswa bukan hanya dari segi kualitas pembelajaran tapi juga dengan efektifitas waktu yang ditawarkan oleh sistem e-learning itu sendiri.

\section{UCAPAN TERIMA KASIH}

Saya ucapan terima kasih atas terbitnya naskah ini pada Seminar Nasional Sains Teknologi dan Inovasi Indonesia 2021 sebagai bagian kolaborasi/kerjasama penelitian dan penulisan ilmiah antar Dosen UPN, UGM dan AAU yang telah terjalin selama ini. Semoga semangat untuk melaksanakan penelitian dan penulisan ilmiah ini terus berkembang dan menjadikan kebutuhan di Lembaga Pendidikan baik di UPN, UGM dan Akademi Angkatan Udara.

\section{REFERENSI}

[1] M. Adnan, “Online learning amid the COVID-19 pandemic: Students perspectives," J. Pedagog. Sociol. Psychol., vol. 1, no. 2, pp. 45-51, Jun. 2020, doi: 10.33902/JPSP.2020261309.

[2] Dhawan, 2020;Dwivedi et al., 2020; Thomas \& Rogers, 2020, "Education, the science of learning, and the COVID-19 crisis".

[3] M. Teräs, J. Suoranta, H. Teräs, and M. Curcher, "Post-Covid-19 Education and Education Technology 'Solutionism': a Seller's Market,” Postdigital Sci. Educ., vol. 2, no. 3, pp. 863-878, Oct. 2020, doi: 10.1007/s42438-020-00164-X.

[4] H. Khatimi, "Mengenal E-Learning Sebagai Salah Satu Bentuk Kegiatan Pembelajaran,” p. 10.

[5] R. Adawi, "Pembelajaran Berbasis E-Learning," p. 12.

[6] R. Dangol and M. Shrestha, "Learning Readiness and Educational Achievement among School Students,” Int. J. Indian Psychol., vol. 7, pp. 467-476, Jun. 2019, doi: 10.25215/0702.056.

[7] C. R. Prihantoro, "Pengaruh E-readiness, E-learning dan E-book pada Implementasi Kurikulum Program Studi D3 Teknologi Mesin terhadap Prestasi Lulusan Program Diploma,” JTP - J. Teknol. Pendidik., vol. 20, no. 2, pp. 105-119, Aug. 2018, doi: 10.21009/jtp.v20i2.8619.

[8] S. Borotis and A. Poulymenakou, "E-Learning Readiness Components: Key Issues to Consider Before Adopting e-Learning Interventions," 2004, pp. 1622-1629. Accessed: Nov. 12, 2021. [Online]. Available: https://www.learntechlib.org/primary/p/11555/ 
[9] Thanh Thi Ngoc Phan1 and Thi Thao Dang2, "Readiness for Online Teaching: A Critical Revi."

[10] L. Romanovich, V. Sevostyanov, M. Romanovich, M. Sevostyanov, and Y. Arkatov, "10.5937/jaes12-7164 = Innovation activity and technology transfer of higher education," Istraz. Proj. Za Privredu, vol. 12, no. 4, pp. 273-276, 2014, doi: 10.5937/jaes12-7164.

[11] N. G. Uğur and A. H. Turan, "Retracted Article: E-learning adoption of academicians: a proposal for an extended model," Behav. Inf. Technol., vol. 37, no. 4, pp. 393-405, Apr. 2018, doi: 10.1080/0144929X.2018.1437219.

[12] Fred D. Davis, "Perceived Usefulness, Perceived Ease of Use, and User Acceptance of Information Technology." https://www.jstor.org/stable/i211386 (accessed Nov. 11, 2021).

[13] J. T. Marchewka and K. Kostiwa, "An Application of the UTAUT Model for Understanding Student Perceptions Using Course Management Software," vol. 7, no. 2, p. 13, 2007.

[14] Viswanath Venkatesh, James Y. L. Thong and Xin Xu, "Consumer Acceptance and Use of Information Technology: Extending the Unified Theory of Acceptance and Use of Technology," vol. 36, No. 1, March 2012.

[15] R. Veloo and M. Masood, "Acceptance and Intention to Use the iLearn System in an Automotive Semiconductor Company in the Northern Region of Malaysia," Procedia - Soc. Behav. Sci., vol. 116, pp. 1378-1382, Feb. 2014, doi: 10.1016/j.sbspro.2014.01.401.

[16] N. Nursiah, "Pengaruh Perceived Ease Of Use Dan Perceived Usefulness Terhadap Behavior Intention To Use," J. Elektron. Sist. Inf. Dan Komput., vol. 3, no. 2, Art. no. 2, Feb. 2018.

[17] E. T. Lwoga, "Antecedents of continued usage intentions of web-based learning management system in Tanzania".

[18] E. Sugiyono, "Metode Penelitian Kuantitatif, Kualitatif, dan R\&D," 2014.

[19] J. F. hair and M. Sarstedt, "Partial least squares structural equation modeling (PLS-SEM): An emerging tool in business research," 4 March 2014, vol. 26 issue 2.

[20] R. Falash, “Analisis Kesiapan Implementasi E-Learning menggunakan E-Learning Readiness Model," vol. 3 no.2, 2017, [Online]. Available: htttps://media.neliti.com

[21] A. P. Teoh and Y. S. Tan, "Predicting Behavioural Intention of Manufacturing Engineers in Malaysia to Use E-Learning in the Workplace," 2020, doi: https://doi.org/10.19173/irrodl.v21i4.4919. 